\title{
ERRATA, VOLUME 58
}

Reinhold Baer, Representations of groups as quotient groups. I. p. 343 , line 23. Read " $c$ " for " $C$."

\section{ERRATA, VOLUME 59}

Y. C. Wong, Contributions to the theory of surfaces in a 4-space of constant curvature.

p. 493, third line above Theorem 5.1. Read " $C$ " for " $C / 3$."

p. 498, equation (6.7). The second equation should read

$$
\delta_{c} B_{0}^{k}=V_{0}^{0} i_{0}^{(2)} i_{0}^{(2)} i_{(3)}^{k}+U_{i}^{0} i_{0}^{(1)} i_{i}^{(1)} i_{(1)}^{k} \text {. }
$$

